\title{
Task 19 - Sampling, Analysis, and Vitrification Study for Thermochem's Steam Reformer Treatment Technology
}

\author{
Semi-Annual Report \\ April 1 - September 30, 1998 \\ TECEIVED \\ MAR 081999 \\ OSTI \\ By \\ Donald P. McCollor; Carolyn M. Lillemoen; Qi Sun
}

Work Performed Under Contract No.: DE-FC21-94MC31388

For

U.S. Department of Energy

Office of Fossil Energy

Federal Energy Technology Center

P.O. Box 880

Morgantown, West Virginia 26507-0880

By

Energy \& Environmental Research Center

University of North Dakota

P. O. Box 9018

Grand Forks, North Dakota 58202-9018 


\section{Disclaimer}

This report was prepared as an account of work sponsored by an agency of the United States Government. Neither the United States Government nor any agency thereof, nor any of their employees, makes any warranty, express or implied, or assumes any legal liability or responsibility for the accuracy, completeness, or usefulness of any information, apparatus, product, or process disclosed, or represents that its use would not infringe privately owed rights. Reference herein to any specific commercial product, process, or service by trade name, trademark, manufacturer, or otherwise does not necessarily constitute or imply its endorsement, recommendation, or favoring by the United States Government or any agency thereof. The views and opinions of authors expressed herein do not necessarily state or reflect those of the United States Government or any agency thereof. 


\section{DISCLAIMER}

Portions of this document may be illegible in electronic image products. Images are produced from the best available original document. 


\section{TABLE OF CONTENTS}

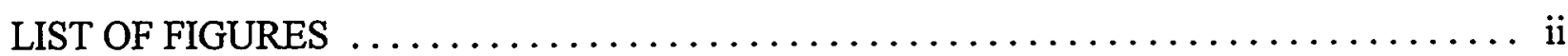

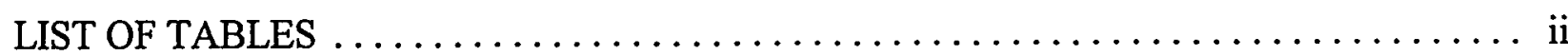

EXECUTIVE SUMMARY $\ldots \ldots \ldots \ldots \ldots \ldots \ldots \ldots \ldots \ldots \ldots \ldots \ldots \ldots \ldots \ldots \ldots$ iii

1.0 BACKGROUND $\ldots \ldots \ldots \ldots \ldots \ldots \ldots \ldots \ldots \ldots \ldots \ldots \ldots \ldots \ldots \ldots \ldots \ldots \ldots \ldots$

2.0 OBJECTIVES $\ldots \ldots \ldots \ldots \ldots \ldots \ldots \ldots \ldots \ldots \ldots \ldots \ldots \ldots \ldots \ldots \ldots \ldots \ldots \ldots \ldots$

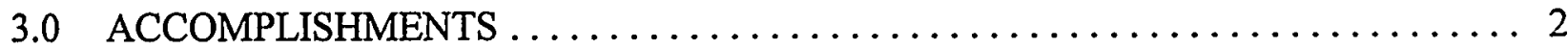

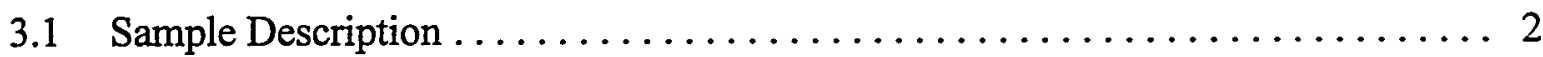

3.2 Chemical Determination of Cerium, Chlorine, and Fluorine in Samples ....... 2

3.2.1 Initial Digestion Methodology for Cerium $\ldots \ldots \ldots \ldots \ldots \ldots \ldots . \ldots \ldots$

3.2.2 Lithium Borate Fusion Digestion Methodology for Cerium .......... 3

3.2.3 Chemical Analysis Methodology for Cerium . ................ 3

3.2.4 Chemical Analysis Methodology for Chlorine $\ldots \ldots \ldots \ldots \ldots \ldots \ldots . . \ldots$

3.2.5 Chemical Analysis Methodology for Fluorine ................. 4

3.3 XRF Analysis Methodology for Cerium and Fluorine $\ldots \ldots \ldots \ldots \ldots \ldots \ldots 4$

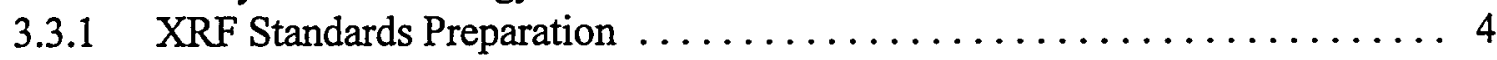

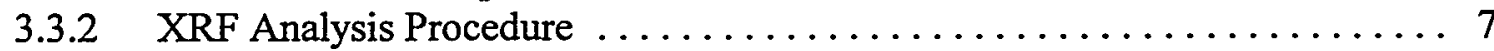

3.4 Analysis Results for Cerium, Chlorine, Fluorine, and Major Elements ....... 8

3.4.1 Chlorine and Fluorine Analysis Results $\ldots \ldots \ldots \ldots \ldots \ldots \ldots \ldots . \ldots$

3.4.2 Major Element Analysis Results . . . . . . . . . . . . . . . . . . 9

3.4.3 Cerium Analysis Results ............................. 9

3.5 Mass Balances of Cerium, Chlorine, and Fluorine $\ldots \ldots \ldots \ldots \ldots \ldots \ldots \ldots \ldots \ldots$

3.6 Thermodynamic Modeling of Cerium Speciation $\ldots \ldots \ldots \ldots \ldots \ldots \ldots \ldots \ldots \ldots$

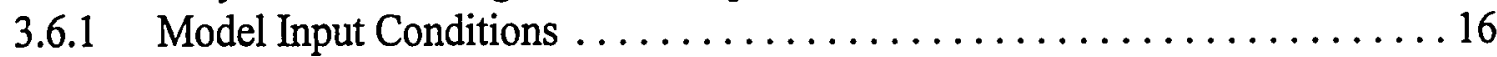

3.6.2 Results of Model Predictions . . . . . . . . . . . . . . . . . . . . 17

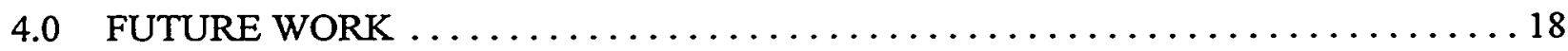

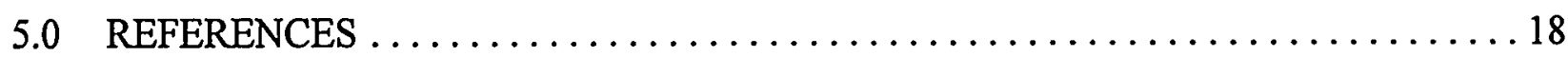




\section{LIST OF FIGURES}

1 Sampling locations for steam reforming process $\ldots \ldots \ldots \ldots \ldots \ldots \ldots \ldots \ldots \ldots$

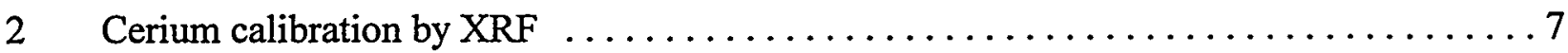

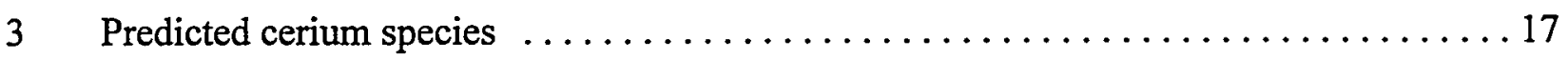

\section{LIST OF TABLES}

1 XRF Standards Used for Cerium and Fluorine Calibration $\ldots \ldots \ldots \ldots \ldots \ldots \ldots$

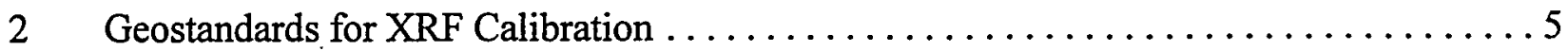

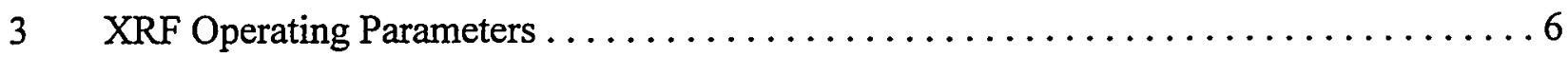

$4 \quad \mathrm{XRF}$ and ICP Cerium Calibration Standards Results $\ldots \ldots \ldots \ldots \ldots \ldots \ldots \ldots \ldots \ldots$

5 Summary of Chemical and XRF Analysis Results for Chlorine and Fluorine $\ldots \ldots \ldots \ldots 8$

6 Summary of Chemical and XRF Analysis Results for Major Elements $\ldots \ldots \ldots \ldots \ldots$

7 Summary of Chemical and XRF Analysis Results for Cerium $\ldots \ldots \ldots \ldots \ldots \ldots$

8 Mass Balances for Cerium, Chlorine, and Fluorine $\ldots \ldots \ldots \ldots \ldots \ldots \ldots \ldots$

9 Input Concentrations Used in FACT Model $\ldots \ldots \ldots \ldots \ldots \ldots \ldots \ldots \ldots \ldots \ldots \ldots \ldots$ 


\section{TASK 19 - SAMPLING, ANALYSIS, AND VITRIFICATION STUDY FOR THERMOCHEM'S STEAM REFORMER TREATMENT TECHNOLOGY}

\section{EXECUTIVE SUMMARY}

Thermochem, Inc., of Columbia, Maryland, has a contract with the Federal Energy Technology Center (FETC) to demonstrate the commercial capability of a steam-reforming process to treat low-level mixed waste (LLMW) from the U.S. Department of Energy (DOE) inventory. The Energy \& Environmental Research Center (EERC) is providing support for Thermochem, Inc., by performing analyses of samples produced during surrogate testing with the reformer, determining temperature-viscosity profiles of the product ash to aid in vitrification analysis, and performing leaching tests on the vitrified ash.

Eighteen samples from the test were analyzed for $\mathrm{Ce}, \mathrm{Cl}$, and $\mathrm{F}$ concentration. Cerium concentrations were determined by inductively coupled plasma (ICP) and x-ray fluorescence (XRF) analysis, chlorine concentrations by ion chromatography (IC) and XRF analysis, and fluorine concentrations by IC analysis.

With samples containing high Ce levels, the XRF analyses indicated significantly higher Ce concentrations than did the ICP analyses using acid digestion. Selected samples were then reanalyzed using a more aggressive lithium borate digestion for the ICP analysis. Although this digestion method reduced the discrepancy, the XRF analyses of these samples still show higher Ce concentrations than do the ICP analyses.

The Ce mass closure improved dramatically from $13.5 \%$ with the acid digestion-ICP data to $77.6 \%$ using the XRF data. The subsequent lithium borate digestion-ICP analysis resulted in an improved closure of $57.2 \%$. The partitioning of $\mathrm{Ce}$ from the XRF analyses indicates that the bulk of the $\mathrm{Ce}, 61 \%$, partitions to the HEPA- 1 filter. The remainder partitions approximately equally, with $18 \%$ to the bed and $21 \%$ to the HEPA-2 filter. The presence of $82 \%$ of the Ce mass in the HEPA filters is consistent with the very small $1-2-\mu \mathrm{m}$ Ce particle sizes observed during examination of the filter sample with scanning electron microscopy (SEM). It may be concluded that the Ce surrogate is remaining within the bed and HEPA filter system.

The mass closures for $\mathrm{Cl}$ by IC and XRF are similar, $21.3 \%$ and $19.6 \%$, respectively. Nearly all the $\mathrm{Cl}$ detected is concentrated in the baghouse, passing the HEPA filters as $\mathrm{HCl}$ gas and being removed by the scrubber. The $\mathrm{F}$ mass closure is very low at $5.3 \%$, with the detected $\mathrm{F}$ primarily in the HEPA-1 filter. The low mass closures for $\mathrm{Cl}$ and $\mathrm{F}$ are not seen as a problem, since reported gas analysis at the exit of the process did not indicate their presence. It is presumed that the remainder of the $\mathrm{Cl}$ and $\mathrm{F}$ have been neutralized by the polishing scrubber and removed in the scrubber water, for which analysis or sample volumes were not provided.

To determine the probable oxidation state and chemical species of cerium in the steam reformer as well as determine the presence of volatile cerium compounds, equilibrium thermodynamic calculations were performed. No gas-phase or liquid-phase cerium species are 
predicted to occur. Cerium is predicted to be present only as solid $\mathrm{CeO}_{2}$ and $\mathrm{CeF}_{3}$ in the system. $\mathrm{CeO}_{2}$ is favored above a temperature of $887^{\circ} \mathrm{F}\left(475^{\circ} \mathrm{C}\right)$, below which both this and $\mathrm{CeF}_{3}$ can occur. Limited SEM morphology and microprobe analysis did not identify significant chlorine or fluorine in combination with $\mathrm{Ce}$, but rather $\mathrm{Ce}$ in combination with small amounts of $\mathrm{Si}, \mathrm{Ca}$, and $\mathrm{Mg}$. Therefore, the dominant cerium form is the oxide, which does not appear to be converted to the fluoride at lower temperatures.

Future work to be performed includes experimental characterization of temperature-viscosity profiles to aid in determining vitrification viability for long-term stabilization. Additionally, calculations of viscosity will be performed for several blend combinations to complement the experimentally determined values. Leachability tests on the vitrified slags will be performed to aid in determining if product leachability falls within EPA guidelines and to assess the suitability of the vitrified material for long-term disposal. 


\section{TASK 19 - SAMPLING, ANALYSIS, AND VITRIFICATION STUDY FOR THERMOCHEM'S STEAM REFORMER TREATMENT TECHNOLOGY}

\subsection{BACKGROUND}

Thermochem, Inc., of Columbia, Maryland, has a contract with the Federal Energy Technology Center (FETC) to demonstrate the commercial capability of a steam-reforming process to treat low-level mixed waste (LLMW) from the U.S. Department of Energy (DOE) inventory. A process development unit is being tested to evaluate the technical and commercial capability of the system to destroy hazardous components with greater than $99.99 \%$ efficiency, isolate and stabilize radionuclides, and reduce the volume of low-level hazardous waste and LLMW. The evaluation tests employ cerium and monoclorobenzene as surrogates for uranium and polychlorinated biphenyls (PCBs).

The Energy \& Environmental Research Center (EERC) is providing support for Thermochem, Inc., in developing a sampling and analysis plan; performing analyses of samples provided by Thermchem, Inc., for chemical composition; determining temperature-viscosity profiles of the steam reformer product to aid in vitrification analysis of the reduced-volume product; and performing leaching tests to aid in determining if product leachability falls within U.S. Environmental Protection Agency (EPA) guidelines.

\subsection{OBJECTIVES}

The overall objective of the project is to provide support to Thermochem, Inc., in the demonstration of the steam reformer treatment technology to treat LLMW. Within this program, specific objectives include the following:

- Analyze cerium, chlorine, and fluorine concentrations in samples from the pilot-scale steam reformer tests to determine partitioning of these elements, mass balances, and changes in concentration with time.

- Perform experimental characterization of temperature-viscosity profiles to aid in determining vitrification viability for long-term stabilization. Additionally, calculations of viscosity will be performed for several blend combinations to complement the experimentally determined values.

- Conduct leachability tests on the vitrified slags to aid in determining if product leachability falls within EPA guidelines and to assess the suitability of the vitrified material for long-term disposal. 


\subsection{ACCOMPLISHMENTS}

\subsection{Sample Description}

Eighteen samples were received from Thermochem, Inc., that had been collected during pilot-scale steam reforming testing. The samples were obtained from locations as shown in Figure 1. These included ten samples of the silica bed and five samples from the HEPA-1 filter taken over the course of the testing. In addition, there were single samples of baghouse and HEPA-2 catches and a composite blended HEPA-1 representing the entire test period.

Two additional samples were requested and obtained as part of the work to establish $\mathrm{Ce}$ closure in the system. These consisted of a sample of the scrubber water and a small portion of the HEPA-1 filter, which had cracked during the course of the test.

\subsection{Chemical Determination of Cerium, Chlorine, and Fluorine in Samples}

\subsubsection{Initial Digestion Methodology for Cerium}

An accurately measured nominal 2-g portion of each solid sample was placed in a $100-\mathrm{mL}$ volumetric flask and $10 \mathrm{~mL}$ of concentrated nitric acid added. The mixture was heated on a hot plate at $150^{\circ} \mathrm{C}$ for 1 hour, cooled, and brought to volume with deionized water for subsequent analysis.

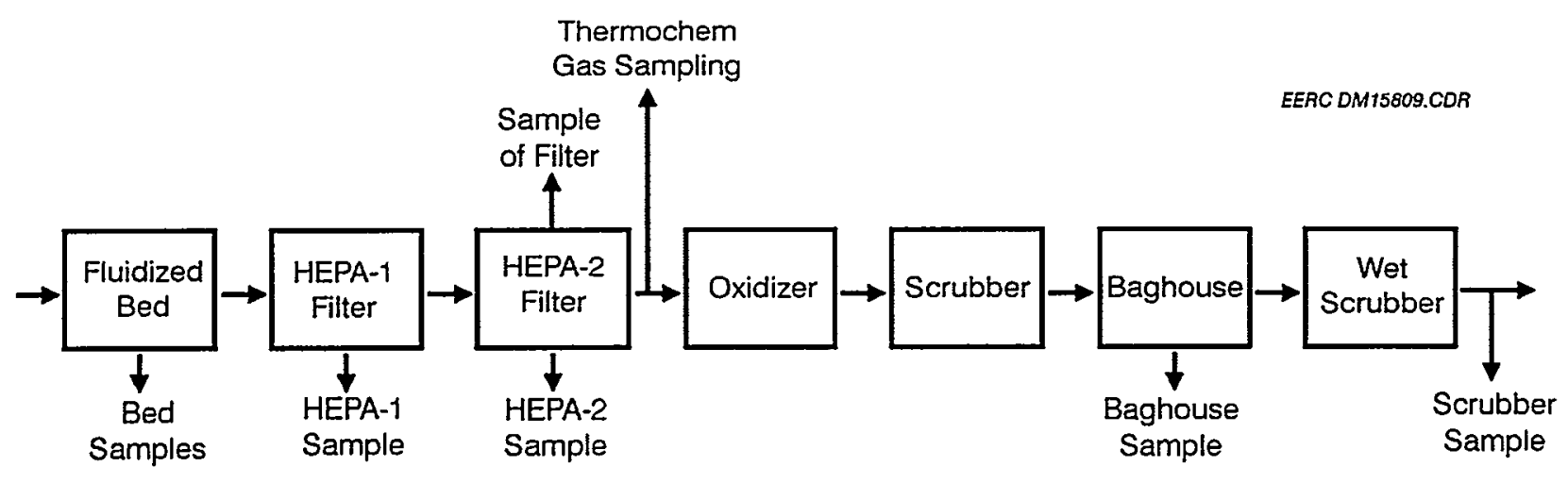

Figure 1. Sampling locations for steam reforming process. 


\subsubsection{Lithium Borate Fusion Digestion Methodology for Cerium}

Discrepancies in the results between $\mathrm{Ce}$ analysis using chemical and $\mathrm{x}$-ray fluorescence (XRF) methods suggested that the acid extraction was not liberating the total amount of $\mathrm{Ce}$ in the samples, a more aggressive $\mathrm{LiBO}_{2}$ fusion method was used to digest selected samples according to the procedure American Society for Testing and Materials (ASTM) C311 (1). Accurately measured $100-\mathrm{mg}$ amounts of sample were mixed with $0.4 \mathrm{~g}$ of $\mathrm{LiBO}_{2}$. A crucible containing the sample was placed in a furnace and heated slowly in $200^{\circ} \mathrm{C}$ increments and held for 5 minutes at each temperature until $950^{\circ} \mathrm{C}$ was attained with the sample held at this temperature for 10 minutes. The sample was then slowly cooled to room temperature with the furnace door slightly open. After reaching room temperature, the fused sample was dissolved in $40 \mathrm{~mL}$ of $12.5 \%$ nitric acid and quantitatively transferred a $100-\mathrm{mL}$ volumetric flask. The flask was brought to volume with deionized water for subsequent analysis. The digestion samples were prepared in duplicate and analyzed separately, with the analysis results averaged if in agreement or the digestion and analysis repeated.

\subsubsection{Chemical Analysis Methodology for Cerium}

The digestion solutions were analyzed by inductively coupled plasma (ICP) spectroscopy using a Leeman Labs, Inc., instrument. The calibration standards and quality control standard were prepared in the same matrix as the sample (10\% nitric acid) to minimize the matrix effects on the instrument. The concentration range of the standards spanned that of the actual samples.

A sample digestion duplicate was run for every ten samples, along with a reagent blank for the digestion quality control. Triplicate readings from one sample digestion solution for every ten samples were performed to verify the instrument precision. A quality control standard made independently of the calibration standards was run immediately after the instrument calibration to verify the calibration curve with the reading within $95 \%-105 \%$ of the standard value. Every ten samples, a known amount of analyte was added to a sample (spike) as a quality control check, with spike recovery within $85 \%-115 \%$ of the expected value.

\subsubsection{Chemical Analysis Methodology for Chlorine}

The sample was prepared using a total leaching procedure. A nominal $10 \mathrm{~g}$ of each sample was accurately weighed and placed in a $100-\mathrm{mL}$ volumetric flask. Approximately $80 \mathrm{~mL}$ of deionized water was introduced into the flask and the mixture sonicated for 1 hour and brought to volume with deionized water.

The leachate from this preparation step was then filtered through a $0.45-\mu \mathrm{m}$ filter and analyzed by ion chromatography (IC) employing a Dionex instrument. Appropriate dilutions were performed if the sample concentration exceeded the concentration of the highest standard.

Sample digestion (leaching) duplicates were performed for every ten samples, and a reagent blank was performed for digestion quality control. Triplicate readings from one sample leachate solution for every ten samples were performed to verify instrument precision. The quality control standard made from a different source than the calibration standards was run to 
verify the calibration curve, with the reading within $95 \%-105 \%$ of the expected value. Every ten samples, a known amount of analyte was added to a sample (spike) as a quality control check, with spike recovery within $85 \%-115 \%$ of the expected value.

\subsubsection{Chemical Analysis Methodology for Fluorine}

The samples were digested using a pyrohydrolysis procedure. In a Leco furnace combustion crucible, an accurately weighed nominal 1-g sample was mixed with $1 \mathrm{~g}$ of $\mathrm{SiO}_{2}$ powder, $2 \mathrm{~g}$ of tin, and $4 \mathrm{~g}$ of iron powder. The mixture was then heated to approximately $1000^{\circ} \mathrm{C}$ for 1 hour in a Leco furnace to undergo pyrohydrolysis. The total fluoride species was trapped by capture of the offgas in a $0.5-\mathrm{M}$ sodium hydroxide impinger solution. The impinger solutions were then analyzed by fluoride ion-selective electrode (ISE).

A sample digestion (pyrohydrolysis) duplicate was performed for every ten samples and a reagent blank performed for digestion quality control. Triplicate readings were obtained from one sample of pyrohydrolate solution for every ten samples analyzed to verify instrument precision. A quality control standard made up independently of the calibration standards was run to verify the calibration curve, with the reading within $95 \%-105 \%$ of the expected value. Every ten samples, a known amount of analyte was added to a sample (spike) as a quality control check, with spike recovery within $85 \%-115 \%$ of the expected value.

\subsection{XRF Analysis Methodology for Cerium and Fluorine}

\subsubsection{XRF Standards Preparation}

After the initial chemical analysis of Ce by ICP-AES (inductively coupled plasma-Auger electron spectroscopy) was reviewed, additional Ce standards were prepared to cover the expected concentrations, as given in Table 1 . To cover the concentration ranges for $\mathrm{Ce}$ and $\mathrm{F}$ by $\mathrm{XRF}$ analysis, calibration standards were prepared by spiking standard reference materials (SRM) with anhydrous $\mathrm{CeF}_{4}$. The materials used for preparing standards were chosen based on their original $\mathrm{Ce}$ and $\mathrm{F}$ content and also on other elements such $\mathrm{Si}, \mathrm{Al}, \mathrm{Fe}, \mathrm{Ca}, \mathrm{Mg}, \mathrm{Na}, \mathrm{K}, \mathrm{P}$, and $\mathrm{Ti}$. The goal was to cover the expected concentration ranges of all of these elements for subsequent sample analysis. In addition to the spiked materials used for $\mathrm{Ce}$ and $\mathrm{F}$ calibration, several other standards were used for calibration of determined major and minor elements. A complete list of these standards and certified concentration values are given in Table 2 .

The standards were prepared by first grinding the starting materials in a SPEX Mixer/Mill to -325 mesh and drying them at $105^{\circ} \mathrm{C}$ for 2 hours. A nominal $6 \mathrm{~g}$ of each SRM was accurately weighed into a clean glass scintillation vial. Different masses of $\mathrm{CeF}_{4}$ were accurately weighed and added to the vials. The final concentrations of $\mathrm{Ce}$ and $\mathrm{F}$ in the standards are given in Table 1. The contents of the vials were mixed well and transferred to a mortar and pestle for more complete mixing. An aliquot was taken and submitted for ICP-AES analysis of $\mathrm{Ce}$ to verify the concentration. Two of the spiked materials were analyzed in duplicate to determine homogeneity of the standard- $-\mathrm{CeF}_{4}$ mixture. 


\section{TABLE 1}

XRF Standards Used for Cerium and Fluorine Calibration.

\begin{tabular}{lcccc}
\hline Standard & Source & $\begin{array}{c}\text { Certified Values } \\
\mathrm{Ce}, \mathrm{F}, \mathrm{wt} \%\end{array}$ & $\begin{array}{c}\text { Spike Added } \\
\mathrm{Ce}, \mathrm{F}, \mathrm{wt} \%\end{array}$ & $\begin{array}{c}\text { Final Concentration } \\
\mathrm{Ce}, \mathrm{F}, \mathrm{wt} \%\end{array}$ \\
\hline GBW07111 & Brammer & $0.0112,0.0840$ & None & $0.0112,0.0840$ \\
STM-1 & .USGS & $0.0259,0.0910$ & None & $0.0259,0.0910$ \\
$\mathrm{GYP}-\mathrm{D}$ & Domtar, Inc. & None & $0.540,0.293$ & $0.540,0.293$ \\
$\mathrm{SDC}-1$ & USGS & $0.0093,0.0595$ & $1.08,0.585$ & $1.0893,0.6445$ \\
$\mathrm{SiO}_{2}$ & Alfa Aesar & None & $2.16,1.17$ & $2.16,1.17$ \\
$\mathrm{SiO}_{2}$ & Alfa Aesar & None & $4.86,2.63$ & $4.86,2.63$ \\
\hline
\end{tabular}

TABLE 2

Geostandards for XRF Calibration

\begin{tabular}{|c|c|c|c|c|c|c|c|}
\hline tandard: & GBW07111 & GYP-DCe & STM-1 ASCRM010 & $\mathrm{SDC}-1 \mathrm{CeF}_{4}$ & $\overline{\mathrm{SiO}_{2}-\mathrm{CeF} \mathrm{S}}$ & $\overline{\mathrm{iO}_{2}-\mathrm{CeF} \mathrm{Si}}$ & $\overline{\mathrm{SiO}_{2}-\mathrm{NaC}}$ \\
\hline Source & Brammer & $\begin{array}{r}\text { Domtar, } \\
\text { Inc. }\end{array}$ & USGS & USGS & $\begin{array}{r}\text { Alfa } \\
\text { Aesar }\end{array}$ & $\begin{array}{r}\text { Alfa } \\
\text { Aesar }\end{array}$ & $\begin{array}{r}\text { Alfa } \\
\text { Aesar }\end{array}$ \\
\hline
\end{tabular}

Concentration, wt\%

\begin{tabular}{lrrrrrrrr}
$\mathrm{Al}_{2} \mathrm{O}_{3}$ & 16.56 & 2.54 & 18.39 & 29.8 & 15.49 & & & \\
$\mathrm{BaO}$ & 0.212 & 0.015 & 0.063 & 0.19 & 0.069 & & & \\
$\mathrm{CaO}$ & 4.72 & 35.30 & 1.09 & 3.27 & 1.377 & & & \\
$\mathrm{Ce}$ & 0.0112 & 0.54 & 0.0259 & & 1.089 & 2.16 & 4.86 & \\
$\mathrm{Cl}$ & 0.023 & 0.0293 & 0.0460 & & 0.0031 & & & 30.33 \\
$\mathrm{Cr}$ & 0.0038 & 0.0014 & & & 0.0059 & & & \\
$\mathrm{~F}$ & 0.084 & 0.293 & 0.091 & & 0.6445 & 1.17 & 2.63 & \\
$\mathrm{Fe}_{2} \mathrm{O}_{3}$ & 6.07 & 1.349 & 5.22 & 12.8 & 6.785 & & & \\
$\mathrm{~K}_{2} \mathrm{O}$ & 3.5 & 0.674 & 4.28 & 0.9 & 3.225 & & & \\
$\mathrm{MgO}$ & 2.81 & 2.162 & 0.1 & 2.11 & 1.662 & & & \\
$\mathrm{MnO}$ & 0.094 & 0.033 & 0.09 & 0.033 & 0.112 & & & \\
$\mathrm{Na}_{2} \mathrm{O}$ & 4.05 & 0.089 & 8.94 & 0.36 & 2.016 & & & 26.5 \\
$\mathrm{P}_{2} \mathrm{O}_{5}$ & 0.34 & 0.0317 & 0.16 & 0.91 & 0.1573 & & & \\
$\mathrm{SiO}_{2}$ & 59.68 & 10.91 & 59.64 & 47.3 & 64.7503 & 96.18 & 92.02 & 42.66 \\
$\mathrm{SO}_{3}$ & 0.0275 & 45.92 & 0.107 & 0.62 & 0.1573 & & & \\
$\mathrm{SrO}_{\mathrm{TiO}_{2}}$ & 0.142 & 0.228 & 0.083 & 0.1 & 0.0216 & & & \\
\hline
\end{tabular}

The standard materials were prepared for XRF by weighing a 2-g portion into a mortar and pestle and adding $2 \mathrm{~mL}$ of liquid cellulose binder. The material and binder were blended thoroughly to obtain a homogeneous mixture, then dried at $50^{\circ} \mathrm{C}$ in a vacuum oven overnight. 
Pressed powder pellets were made with a SPEX pellet press and die. An additional certified SRM was prepared as a quality control standard to verify the instrument calibration.

The Rigaku RIX 2100 XRF spectrometer used for calibration and analysis is equipped with a rhodium target end-window $\mathrm{X}$-ray tube operating at $3.0 \mathrm{~kW}$, a 50 -position sample changer, six diffraction crystals, and two detectors: scintillation counter (SC) and gas flow proportional counter (PC). The spectrometer is computer controlled with OS/2 applications software. The selection of analytical lines and operating parameters are listed in Table 3 . The collimator setting for all analytical lines was set at a slit width of $450 \mu \mathrm{m}$. During the initial calibration for Ce and F, appropriate measuring conditions and background corrections were selected. It was quickly determined that low levels of $F(<1 \%)$ could not be quantitatively determined by the XRF spectrometer. The diffraction crystal used in the instrument to determine light elements $(\mathrm{N}-\mathrm{Mg})$ such as $F$ is the RX40 crystal. Unfortunately, spectral overlaps from the $F e L_{\alpha}$ and $F e L_{\beta 1}$ lines interfere significantly with $F \mathrm{~K}_{\alpha}$ determination. Because of the low $\mathrm{x}$-ray intensity emitted by light elements such $\mathrm{F}$, selecting alternative analytical lines for $\mathrm{F}$ determination were not an option since their intensities are magnitudes lower than the $\mathrm{K}_{\alpha}$ line.

Instrument calibration was performed using the Ce standards listed in Table 1 . These were analyzed and the resultant intensities were plotted against concentration values. The regression correlation coefficient $\left(R^{2}\right)$ for Ce was 0.99638 . The calibration curve is shown in Figure 2. Because of low sensitivity and spectral overlaps, the XRF spectrometer was not calibrated for $F$ determination.

\section{TABLE 3}

XRF Operating Parameters

\begin{tabular}{lcccc}
\hline Analyzed Element & Line & Diffraction Crystal & $2 \theta$ angle & $\mathrm{kV} / \mathrm{mA}$ \\
\hline $\mathrm{Al}$ & $\mathrm{K}_{\alpha}$ & $\mathrm{PET}$ & 144.75 & $50 / 50$ \\
$\mathrm{Ca}$ & $\mathrm{K}_{\alpha}$ & $\mathrm{Ge}$ & 61.95 & $50 / 50$ \\
$\mathrm{Ce}$ & $\mathrm{L}_{\alpha}$ & $\mathrm{LiF} 200$ & 79.14 & $50 / 50$ \\
$\mathrm{Cl}$ & $\mathrm{K}_{\alpha}$ & $\mathrm{Ge}$ & 92.80 & $50 / 50$ \\
$\mathrm{Fe}$ & $\mathrm{K}_{\alpha}$ & $\mathrm{LiF} 200$ & 57.52 & $50 / 50$ \\
$\mathrm{~K}$ & $\mathrm{~K}_{\alpha}$ & $\mathrm{Ge}$ & 69.95 & $50 / 50$ \\
$\mathrm{Mg}$ & $\mathrm{K}_{\alpha}$ & $\mathrm{RX} 40$ & 14.15 & $50 / 50$ \\
$\mathrm{Na}$ & $\mathrm{K}_{\alpha}$ & $\mathrm{RX} 40$ & 17.15 & $50 / 50$ \\
$\mathrm{P}$ & $\mathrm{K}_{\alpha}$ & $\mathrm{Ge}$ & 141.05 & $50 / 50$ \\
$\mathrm{~S}$ & $\mathrm{~K}_{\alpha}$ & $\mathrm{Ge}$ & 10.75 & $50 / 50$ \\
$\mathrm{Si}$ & $\mathrm{K}_{\alpha}$ & $\mathrm{PET}$ & 109.05 & $50 / 50$ \\
$\mathrm{Ti}$ & $\mathrm{K}_{\alpha}$ & $\mathrm{LiF} 200$ & 86.12 & $50 / 50$ \\
\hline
\end{tabular}

Five of the six standards used for calibration were also analyzed by ICP-AES. Table 4 lists the results obtained by both the XRF and ICP-AES. The calculated detection limit for Ce by XRF was determined to be $200 \mathrm{ppm}$; therefore, the first standard labeled GBW07111 was omitted from the calibration and a higher standard was added. 


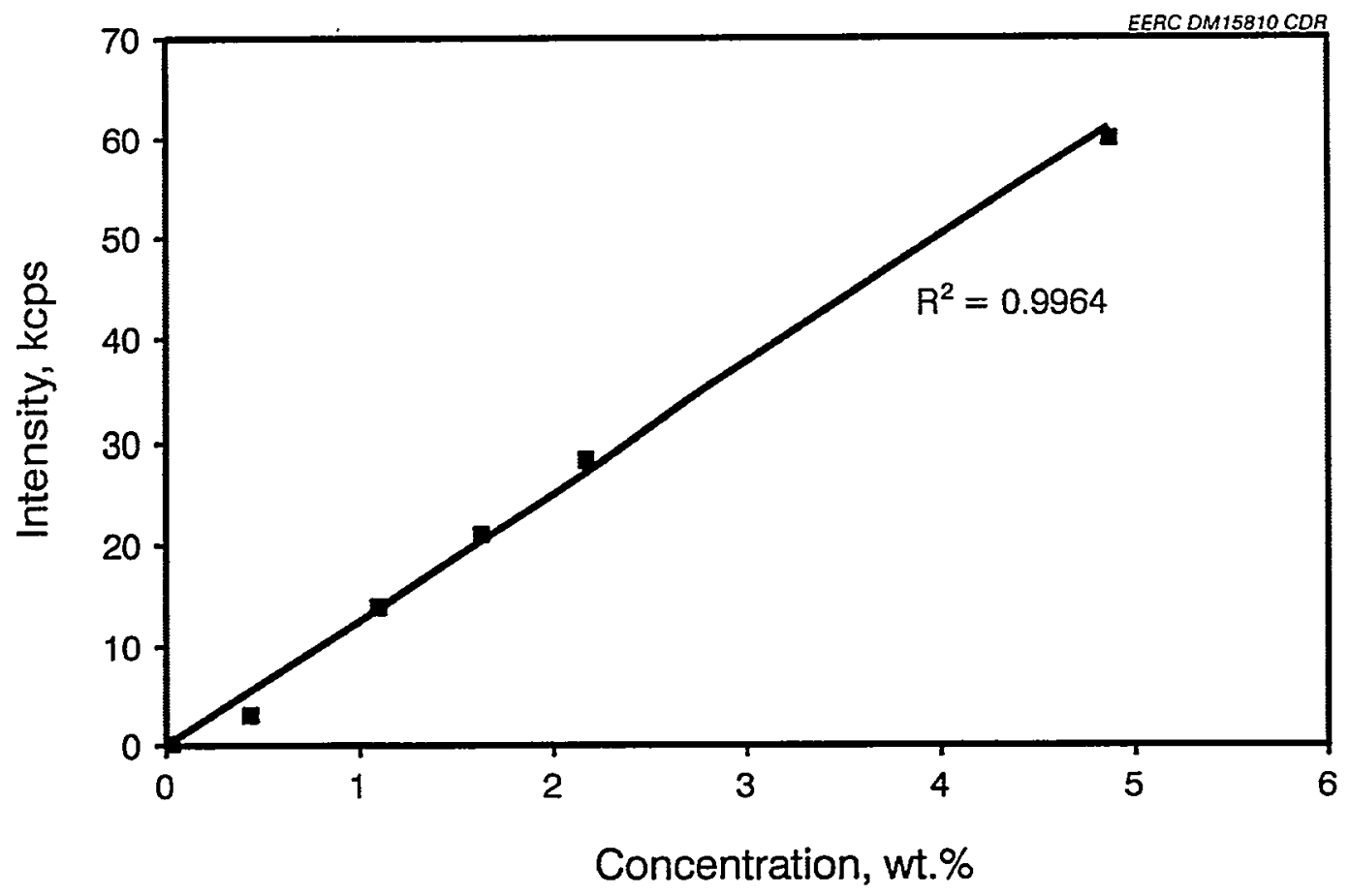

Figure 2. Cerium calibration by XRF.

TABLE 4

XRF and ICP Cerium Calibration Standards Results

\begin{tabular}{lccc}
\hline Standard & Reference Value, wt $\%$ & XRF, wt $\%$ & ICP-AES, wt\% \\
\hline GBW07111 & 0.0112 & 0.021 & 0.010 \\
STM-1 & 0.0259 & 0.027 & 0.0343 \\
GYP-D & 0.540 & 0.510 & 0.424 \\
SDC-1 & 1.09 & 1.05 & 1.14 \\
$\mathrm{SiO}_{2}$ & 2.16 & 2.15 & 1.99 \\
\hline
\end{tabular}

\subsubsection{XRF Analysis Procedure}

The reformer samples were pulverized and pressed into pellets in a manner similar to the preparation of the standards. Ce quantification was made using the calibration obtained from the standard as described previously, along with quantification of $\mathrm{Cl}$ and major elements. Because of the high detection limit for $\mathrm{F}$, no F quantification was performed. A quality control calibration standard was analyzed every five samples. In addition, replicate analyses were performed on two of the samples and analyses performed on duplicate pellets of two additional samples. 


\subsection{Analysis Results for Cerium, Chlorine, Fluorine, and Major Elements}

\subsubsection{Chlorine and Fluorine Analysis Results}

The chemical and XRF analysis results obtained for $\mathrm{Cl}$ and $\mathrm{F}$ concentrations in the Thermochem, Inc., samples are given in Table 5, with the samples obtained from the sampling locations over the course of the pilot-scale steam reforming test as shown in Figure 1. Eight samples were initially analyzed for $\mathrm{Cl}$ by digestion and IC. As the initial as well as final bed and HEPA-1 filter samples showed very low $\mathrm{Cl}$ levels, additional analysis of the intermediate samples

\section{TABLE 5}

Summary of Chemical and XRF Analysis Results for Chlorine and Fluorine

\begin{tabular}{|c|c|c|c|c|c|c|}
\hline Sample & & $\begin{array}{l}\text { Elapsed } \\
\text { Time, hr }\end{array}$ & $\begin{array}{l}\text { XRF } \\
\mathrm{Cl}, \\
\mu \mathrm{g} / \mathrm{g}\end{array}$ & $\begin{array}{l}\mathrm{IC} \\
\mathrm{Cl}, \\
\mu \mathrm{g} / \mathrm{g}\end{array}$ & $\begin{array}{l}\mathrm{IC} \\
\mathrm{F} \\
\mu \mathrm{g} / \mathrm{g}\end{array}$ & \\
\hline 3 & Bed & 22.2 & $<100$ & 5.0 & 68.6 & \\
\hline 8 & Bed & 126.2 & $<100$ & 5.0 & 8.9 & \\
\hline 9 & HEPA-1 & 126.2 & $<100$ & 11 & 24 & \\
\hline 10 & HEPA-1 & 134.2 & $\begin{array}{l}<100 \\
<100^{a}\end{array}$ & NA & 52.7 & \\
\hline 11 & Bed & 135.6 & $<100$ & NA & 27 & \\
\hline 12 & Bed & 193.9 & $<100$ & NA & 14 & \\
\hline 13 & Bed & 193.9 & $<100$ & NA & 13 & \\
\hline 14 & Bed & 380.0 & $<100$ & NA & 95.7 & High-feed test \\
\hline 15 & Bed & 386.0 & $<100$ & NA & 54.3 & High-feed test \\
\hline 16 & Bed & 409.5 & $<100$ & NA & 55.7 & High-feed test \\
\hline 17 & HEPA-1 & 409.5 & $\begin{array}{l}<100 \\
<100^{b}\end{array}$ & NA & 70.5 & High-feed test \\
\hline 18 & Bed & 434.0 & $<100$ & NA & 19 & \\
\hline 19 & HEPA-1 & 434.0 & $\begin{array}{l}<100 \\
<100^{a} \\
<100^{a}\end{array}$ & NA & 136 & \\
\hline 21 & Bed & 599.0 & $<100$ & 10 & 21.4 & \\
\hline 22 & HEPA-1 & 599.0 & $<100$ & 7 & 89.5 & \\
\hline 23 & HEPA-2 & 599.0 & $\begin{array}{l}600 \\
370^{b}\end{array}$ & 442 & 312 & \\
\hline 24 & Baghouse & 599.0 & 379000 & 401000 & 3220 & \\
\hline 25 & Mixed HEPA-1 & NA & $<100$ & 36 & 169 & Composite sample \\
\hline
\end{tabular}

${ }^{a}$ Duplicate analysis of the same sample.

b Duplicate sample prepared. 
was not performed by IC. XRF analysis was performed on all samples, with the results confirming the expected very low bed and HEPA-1 Cl concentrations. Analysis for $\mathrm{F}$, as for $\mathrm{Cl}$, was performed by digestion and IC. Although the XRF analysis method was working close to the lower detection limit for $\mathrm{Cl}$, there is reasonable agreement between the IC and $\mathrm{XRF} \mathrm{Cl}$ analysis results. Although it is theoretically possible to perform $\mathrm{F}$ analysis by $\mathrm{XRF}$, it was determined that the $\mathrm{F}$ concentrations were simply below the instrument detection limit. Accordingly, no XRF F analyses are reported.

The highest chlorine concentration was found in the baghouse sample after the $\mathrm{NaOH}$ polishing scrubber, as would be expected for gaseous $\mathrm{HCl}$ formed in the process. A much smaller concentration was captured in the HEPA-2 filter as fine particulate. Effectively no $(90 \mu \mathrm{g} / \mathrm{g}$ or less) chlorine was found in the HEPA-1 filter catches or the bed material.

Fluorine, like chlorine, has the highest concentration in the baghouse sample, with moderate concentrations captured as fine particulate in the HEPA-2 and HEPA-1 samples. Bed fluorine concentrations were relatively low, ranging from 9 to $96 \mu \mathrm{g} / \mathrm{g}$. The effect of two short-period tests with increased concentration in the feed at 380-409 hours into the test was reflected in a small increase in fluorine concentration in the bed and HEPA-1 samples. The bed fluorine level decreased again, suggesting that it migrated out of the bed into the HEPA filters and baghouse with time.

\subsubsection{Major Element Analysis Results}

Along with $\mathrm{Ce}$ and $\mathrm{F}$, the major elements were determined for the samples by XRF analysis. These results are given in Table 6, expressed as oxide weight percents. The dominant element in the bed and HEPA-1 samples is $\mathrm{SiO}_{2}$, as would be expected from the sand bed used for the tests. An increase in calcium concentration both in the bed and HEPA-1 filter occurred between 380 and 434 hours into the test, apparently associated with the high-feed rate portion of the test. The calcium level then gradually decreased again in subsequent samples. The mixed HEPA-1 composite sample shows a calcium level $(5.8 \%)$ that is higher than any of the intermediate bed or HEPA-1 samples taken during the course of the test. The HEPA-2 filter has quite a high calcium concentration (28.6\%) along with elevated magnesium (3.8\%), iron (1.3\%), and sodium ( $0.6 \%)$. The baghouse samples contain primarily sodium and chlorine as a result of the $\mathrm{HCl}$ scrubbing with caustic. Sulfur is also present, presumably from scrubbing $\mathrm{SO}_{2}$ from the product gases. Some calcium, magnesium, and silica are also present, resulting from either the scrubbing out of very fine particulate or impurities in the caustic used.

\subsubsection{Cerium Analysis Results}

Cerium concentrations were determined both by ICP and XRF analysis. With samples containing high Ce levels, the XRF analyses indicated significantly higher Ce concentrations than did the ICP analyses using acid digestion. Selected samples were then reanalyzed using a more aggressive lithium borate digestion for the ICP analysis. Although this digestion method reduced the discrepancy, the XRF analyses of these samples still show higher Ce concentrations than do the ICP analyses. These results are given in Table 7.

Cerium was concentrated in the HEPA-2 sample, with intermediate concentrations in the HEPA-1 samples. Again, the HEPA-1 sample concentrations show the effect of the two short high- 


\section{TABLE 6}

Summary of Chemical and XRF Analysis Results for Major Elements

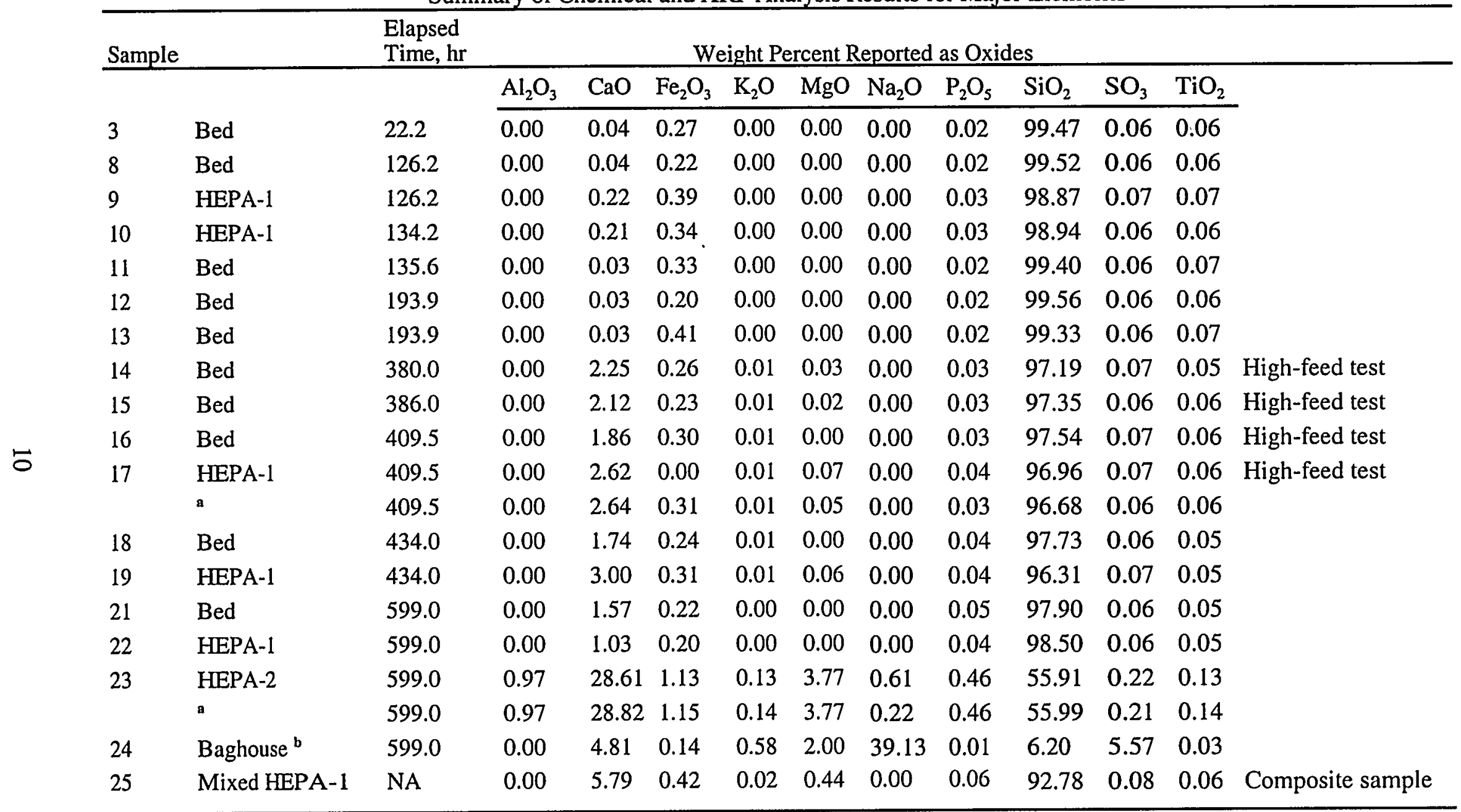

Duplicate sample analysis.

b $37.90 \% \mathrm{Cl}$ in sample. 


\section{TABLE 7}

Summary of Chemical and XRF Analysis Results for Cerium

\begin{tabular}{|c|c|c|c|c|c|}
\hline Sample & $\begin{array}{l}\text { Elapsed } \\
\text { Time, hr }\end{array}$ & $\begin{array}{l}\text { XRF } \\
\mathrm{Ce}, \\
\mu \mathrm{g} / \mathrm{g}\end{array}$ & $\begin{array}{l}\text { First } \\
\text { ICP } \\
\mathrm{Ce}, \\
\mu \mathrm{g} / \mathrm{g}\end{array}$ & $\begin{array}{l}\text { Second } \\
\mathrm{ICP} \\
\mathrm{Ce}, \\
\mu \mathrm{g} / \mathrm{g}\end{array}$ & \\
\hline $3 \mathrm{Bed}$ & 22.2 & $<100$ & 14.0 & $\mathrm{NA}$ & \\
\hline 8 Bed & 126.2 & $<100$ & 27.0 & $\mathrm{NA}$ & \\
\hline 9 HEPA- 1 & 126.2 & 5670 & 183 & $\mathrm{NA}$ & \\
\hline \multirow[t]{2}{*}{10 HEPA- 1} & 134.2 & 5750 & 140 & $\mathrm{NA}$ & \\
\hline & & $5910^{a}$ & & & \\
\hline $11 \mathrm{Bed}$ & 135.6 & $<100$ & 20.0 & $\mathrm{NA}$ & \\
\hline $12 \mathrm{Bed}$ & 193.9 & $<100$ & 13.0 & $\mathrm{NA}$ & \\
\hline $13 \mathrm{Bed}$ & 193.9 & $<100$ & 7.9 & $\mathrm{NA}$ & \\
\hline $14 \mathrm{Bed}$ & 380.0 & $<100$ & 129.0 & NA & High-feed test \\
\hline $15 \mathrm{Bed}$ & 386.0 & $<100$ & 144.0 & NA & High-feed test \\
\hline $16 \mathrm{Bed}$ & 409.5 & 630 & 224 & $\mathrm{NA}$ & High-feed test \\
\hline \multirow[t]{2}{*}{17 HEPA-1 } & 409.5 & 1220 & 1860 & $\mathrm{NA}$ & High-feed test \\
\hline & & $1240^{b}$ & $1860^{c}$ & & \\
\hline $18 \mathrm{Bed}$ & 434.0 & 460 & 208 & $\mathrm{NA}$ & \\
\hline \multirow[t]{3}{*}{19 HEPA-1 } & 434.0 & 760 & 2130 & $\mathrm{NA}$ & \\
\hline & & $720^{a}$ & & & \\
\hline & & $850^{a}$ & & & \\
\hline $21 \mathrm{Bed}$ & 599.0 & 930 & 204 & 970 & \\
\hline \multirow[t]{3}{*}{22 HEPA-1 } & 599.0 & 230 & 225 & $\mathrm{NA}$ & \\
\hline & & & $233^{b}$ & & \\
\hline & & & $238^{c}$ & & \\
\hline \multirow[t]{2}{*}{23 HEPA-2 } & 599.0 & 75800 & 22000 & 39842 & \\
\hline & & $76700^{\mathrm{b}}$ & & & \\
\hline 24 Baghouse & 599.0 & $<100$ & 5 & $\mathrm{NA}$ & \\
\hline 25 Mixed HEPA-1 & NA & 3700 & 451 & 2660 & $\begin{array}{l}\text { Composite } \\
\text { sample }\end{array}$ \\
\hline Filter Material & NA & NA & 31 & NA & \\
\hline Scrubber Solution & NA & $\mathrm{NA}$ & $<0.2$ & $\mathrm{NA}$ & \\
\hline
\end{tabular}

${ }^{a}$ Duplicate analysis of the same sample.

${ }^{b}$ Duplicate sample prepared.

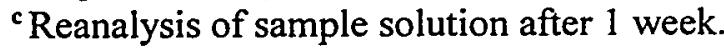


high Ce concentration in the HEPA-1 filter early on in the test. The bed samples show a relatively low, but generally increasing Ce level from the beginning to end of the test. Cerium concentration in the baghouse sample was below the detection limit, indicating that essentially no Ce reached the baghouse. ICP analysis of the scrubber solution and HEPA-1 filter material itself confirms that no $\mathrm{Ce}$ was passing the HEPA filters, nor that significant Ce was being retained in the filter itself.

\subsection{Mass Balances of Cerium, Chlorine, and Fluorine}

Obtaining a mass balance of $\mathrm{Ce}$ in the reformer system is of importance, first, in demonstrating that the surrogate is retained in the system and second, in determining the distribution of the surrogate between bed and filters. Previous $\mathrm{Ce}$ analysis performed by a contract laboratory for Thermochem indicated a very low closure of the Ce mass balance. The initial $\mathrm{Ce}$ analyses performed by the EERC using acid digestion and ICP analysis was planned to verify the contract laboratory results. The XRF analyses would provide a second verification of the $\mathrm{Ce}$ analyses using a different analysis method. The initial ICP Ce analyses using acid digestion, which were reported to be comparable with the results obtained by the contract laboratory, were presented in the previous semiannual report. However, these analyses did not significantly improve the closure of the $\mathrm{Ce}$ mass balance.

Gas and particulate analyses had been performed on the gas stream exiting the HEPA-2 filter during the test, with the results indicating that no Ce was passing the filters. Pending the results of the XRF analyses, an effort was made to determine if $\mathrm{Ce}$ in the form of fine particulate was passing both the HEPA filters and baghouse or being retained in the filters themselves. A sample of liquid scrubber solution and a sample of a cracked HEPA filter were obtained for analysis. $\mathrm{Ce}$ in the liquid scrubber solution was below detection limits, and only a small concentration of $\mathrm{Ce}$ was found in the filter material. These results confirmed that the Ce was not passing the HEPA filters or being retained in the filters themselves.

The XRF analysis results indicated significantly higher Ce concentration than those obtained by the ICP analyses using acid digestion. Previous examination of the HEPA-2 sample using scanning electron microscopy (SEM) and microprobe analysis had indicated that the Ce particles were associated with $\mathrm{Si}, \mathrm{Ca}$, and $\mathrm{Mg}$. The acid digestion procedure initially used is based on the premise that $\mathrm{Ce}$ is in a pure chemical form, such as an oxide or chloride. Such a digestion would not be effective if the Ce had been partially assimilated into a low-melting-point calcium-magnesium silicate slag phase. Accordingly, selected samples were reanalyzed using a lithium borate digestion procedure, which would be more effective at dissolution of $\mathrm{Ce}$ from such a matrix. Although the $\mathrm{Ce}$ concentrations obtained by this method were significantly higher than previously, they still are somewhat lower than the XRF results.

Using the average feed rates for the test provided by Thermochem and concentrations obtained for the final bed, mixed HEPA-1 filter, the HEPA-2 filter, and the baghouse, a mass balance was performed for $\mathrm{Ce}, \mathrm{Cl}$, and $\mathrm{F}$. This mass balance is given in Table 8 . This mass balance should be considered only approximate and is used to show the improvement in Ce closure and the partitioning of $\mathrm{Ce}, \mathrm{Cl}$, and $\mathrm{F}$ between the various sample catches. 
TABLE 8

Mass Balances for Cerium, Chlorine, and Fluorine

\begin{tabular}{lccc}
\hline & First ICP & XRF & Second ICP \\
& Analysis & Analysis & Analysis \\
\hline Cerium & &
\end{tabular}

\begin{tabular}{|c|c|c|c|c|c|c|c|c|c|c|}
\hline \multirow[t]{2}{*}{ Total Ce Fed, lb } & 2.276 & & & & & & & & & \\
\hline & $\begin{array}{c}\text { Mass, } \\
\mathrm{lb}^{\mathrm{a}}\end{array}$ & $\begin{array}{l}\text { Conc., } \\
\mu \mathrm{g} / \mathrm{g}\end{array}$ & $\begin{array}{l}\text { Wt., } \\
\text { lb }\end{array}$ & Percent & $\begin{array}{c}\text { Conc., } \\
\mu \mathrm{g} / \mathrm{g}\end{array}$ & $\begin{array}{c}\text { Wt., } \\
\mathrm{lb}\end{array}$ & Percent & $\begin{array}{c}\text { Conc., } \\
\mu \mathrm{g} / \mathrm{g}\end{array}$ & $\begin{array}{c}\text { Wt., } \\
\text { lb }\end{array}$ & Percent \\
\hline Final Bed & 343.00 & 204 & 0.06997 & 22.75 & 930 & 0.31899 & 18.05 & 970 & 0.33271 & 25.55 \\
\hline Mixed HEPA-1 & 292.58 & 451 & 0.13195 & 42.91 & 3700 & 1.08255 & 61.25 & 2660 & 0.77826 & 59.76 \\
\hline HEPA-2 & 4.80 & 22000 & 0.10560 & 34.34 & 76250 & 0.36600 & 20.71 & 39842 & 0.19124 & 14.69 \\
\hline Baghouse & 2.00 & 5 & 0.00001 & 0.00 & 0 & 0.00000 & 0.00 & 0 & 0.00000 & 0.00 \\
\hline Total & & & 0.30754 & & & 1.76754 & & & 1.30221 & \\
\hline Closure, \% & & & 13.51 & & & 77.65 & & & 57.21 & \\
\hline
\end{tabular}

\section{Chlorine}

Total $\mathrm{Cl} \mathrm{Fed,} \mathrm{lb}$ 3.89

\begin{tabular}{|c|c|c|c|c|c|c|c|}
\hline & $\begin{array}{c}\text { Mass, } \\
\mathrm{lb}^{\mathrm{a}}\end{array}$ & $\begin{array}{l}\text { Conc., } \\
\mu \mathrm{g} / \mathrm{g}\end{array}$ & $\begin{array}{c}\text { Wt., } \\
\text { lb }\end{array}$ & Percent & $\begin{array}{l}\text { Conc., } \\
\mu \mathrm{g} / \mathrm{g}\end{array}$ & $\begin{array}{c}\text { Wt., } \\
\mathrm{lb}\end{array}$ & Percent \\
\hline Final Bed & 343.00 & 10 & 0.00343 & 0.41 & 0 & 0.00000 & 0.00 \\
\hline Mixed HEPA-1 & 292.58 & 7 & 0.00205 & 0.25 & 0 & 0.00000 & 0.00 \\
\hline HEPA-2 & 4.80 & 442 & 0.00212 & 0.26 & 600 & 0.00288 & 0.38 \\
\hline Baghouse & 2.00 & 410000 & 0.82000 & 99.08 & 379000 & 0.75800 & 99.62 \\
\hline Total & & & 0.82760 & & & 0.76088 & \\
\hline Closure, \% & & & 21.30 & & & 19.58 & \\
\hline
\end{tabular}


TABLE 8 (continued)

\begin{tabular}{|c|c|c|c|c|c|}
\hline & & \multicolumn{2}{|c|}{$\begin{array}{l}\text { First ICP } \\
\text { Analysis } \\
\end{array}$} & $\begin{array}{c}\text { XRF } \\
\text { Analysis } \\
\end{array}$ & $\begin{array}{c}\text { Second ICP } \\
\text { Analysis } \\
\end{array}$ \\
\hline \multicolumn{6}{|l|}{ Fluorine } \\
\hline \multirow[t]{2}{*}{ Total F Fed, lb } & 1.22 & & & & \\
\hline & $\begin{array}{c}\text { Mass, } \\
\mathrm{lb}^{\mathrm{a}} \\
\end{array}$ & $\begin{array}{l}\text { Conc., } \\
\mu \mathrm{g} / \mathrm{g}\end{array}$ & $\begin{array}{l}\text { Wt., } \\
\mathrm{lb}\end{array}$ & Percent & \\
\hline Final Bed & 343.00 & 21.4 & 0.00734 & 11.34 & \\
\hline Mixed HEPA-1 & 292.58 & 169 & 0.04945 & 76.40 & \\
\hline HEPA-2 & 4.80 & 312 & 0.00150 & 2.31 & \\
\hline Baghouse & 2.00 & 3220 & 0.00644 & 9.95 & \\
\hline Total & & & 0.06472 & & \\
\hline Closure, \% & & & 5.33 & & \\
\hline
\end{tabular}

$\mp$ a Total mass reported in bed, HEPA-1, HEPA-2, and baghouse. 
The Ce mass closure improved dramatically, from $13.5 \%$ with the acid digestion-ICP data to $77.6 \%$ using the XRF data. The subsequent lithium borate digestion-ICP analysis resulted in an improved closure of $57.2 \%$. The partitioning of Ce from the XRF analyses indicates that the bulk of the $\mathrm{Ce}, 61 \%$, partitions to the HEPA-1 filter. The remainder partitions approximately equally, with $18 \%$ to the bed and $21 \%$ to the HEPA- 2 filter. The presence of $82 \%$ of the Ce mass in the HEPA filters is consistent with the very small, $1-2-\mu \mathrm{m}$ Ce particle sizes observed during examination of the filter sample with SEM. Such fine particulate would be expected to be blown out of the fluidized sand bed and collected in the filters. Although both the bed and the HEPA-1 sample have low-tomoderate Ce concentrations, together they comprise nearly all the sample mass in the system. The XRF analysis method is thus measuring Ce concentrations in the range of $0.4 \%-0.09 \%$ at these lower concentrations, increasing the relative error. A small increase in the Ce concentration of either the bed or HEPA-1 filter will significantly increase the Ce mass reported because of the large sample mass involved. It may be concluded that the Ce surrogate is remaining within the bed and HEPA filter system and that the unreported $22 \%$ of the Ce is attributable to sample inhomogeneities and to uncertainty in the analysis concentrations.

The mass closures for $\mathrm{Cl}$ by IC and XRF are similar, $21.3 \%$ and $19.6 \%$, respectively. Nearly all the $\mathrm{Cl}$ detected is concentrated in the baghouse, passing the HEPA filters as $\mathrm{HCl}$ gas and being removed by the scrubber. The $\mathrm{F}$ mass closure is very low at $5.3 \%$, with the detected $\mathrm{F}$ primarily in the HEPA-1 filter. The low mass closures for $\mathrm{Cl}$ and $\mathrm{F}$ are not seen as a problem, since reported gas analysis at the exit of the process did not indicate their presence. It is presumed that the remainder of the $\mathrm{Cl}$ and $\mathrm{F}$ have been neutralized by the polishing scrubber and removed in the scrubber water, for which analysis or sample volumes were not provided.

\subsection{Thermodynamic Modeling of Cerium Speciation}

To determine the probable oxidation state and chemical species of cerium in the steam reformer as well as determine the presence of volatile cerium compounds, equilibrium thermodynamic calculations were performed using the FACT code (2). FACT determines the amounts of solid, liquid, and gas species present as a function of temperature using the minimization of Gibb's free energy. Although the program has an upper limit on the total number of species, in the present calculations it was possible to simultaneously consider all possible solid, liquid, and gas species available in the FACT database. Gas-phase species are modeled as an ideal gas mixture, and all liquid-phase species as forming a single ideal solution, rather than as individual liquids. Solidphase species are considered as individual solid phases.

Since FACT models equilibrium processes, the concentration of major products of gasification $\left(\mathrm{CO}, \mathrm{CO}_{2}, \mathrm{H}_{2}, \mathrm{CH}_{4}\right)$ are predicted to change with decreasing temperature from their concentrations at formation due to interconversion. In reality, these concentrations remain almost constant because of kinetic restraints on the conversions. However, this has only a very slight effect on other species present.

FACT has a quite extensive compound database. However, this does not preclude the possible existence of other cerium compounds in the reforming process that are not included in this database. 


\subsubsection{Model Input Conditions}

Table 9 gives the amounts of species used as input. The bed composition used is based on the $\mathrm{XRF}$ analysis of the Sample 21 final bed material. The other quantities are based on material fed and gases produced for a 1-hour time period. $\mathrm{CeO}_{2}, \mathrm{CeF}_{3}$, and $\mathrm{Cl}$ amounts were calculated using the average feed rate. Organic pad material is not included, as this mass appears in the product gas formed. Gas composition was taken from data provided by Thermochem, Inc., for the test, and gas mass flow over a 1-hour period determined from the HEPA-2 exit gas flow rate. The " $\mathrm{C}_{x} \mathrm{H}_{\mathrm{y}}$ " was assumed to be $\mathrm{CH}_{4}$ for purposes of calculating input masses. Calculations were performed at $45^{\circ} \mathrm{F}$ $\left(25^{\circ} \mathrm{C}\right)$ increments over a temperature range of $1202^{\circ}-392^{\circ} \mathrm{F}\left(650^{\circ}-200^{\circ} \mathrm{C}\right)$, corresponding to temperatures from that of the reformer bed temperature to that of the HEPA-2 filter exit temperature at a total pressure of $1 \mathrm{~atm}$.

\section{TABLE 9}

\begin{tabular}{|c|c|}
\hline Species & Weight, $\mathrm{g}$ \\
\hline $\mathrm{H}_{2}$ & 17.30 \\
\hline $\mathrm{CO}$ & 24.23 \\
\hline $\mathrm{CO}_{2}$ & 590.07 \\
\hline Hydrocarbons ${ }^{a}$ & 2941.04 \\
\hline $\mathrm{H}_{2} \mathrm{O}$ & 61720.38 \\
\hline $\mathrm{O}_{2}$ & 539.77 \\
\hline $\mathrm{N}_{2}$ & 18807.10 \\
\hline $\mathrm{CeO}_{2}$ & 0.71 \\
\hline $\mathrm{CeF}_{3}$ & 1.70 \\
\hline $\mathrm{Cl}$ & 2.94 \\
\hline
\end{tabular}

$\mathrm{SiO}_{2}$

153092.07

$\mathrm{Al}_{2} \mathrm{O}_{3}$

0.00

$\mathrm{Fe}_{2} \mathrm{O}_{3}$

311.16

$\mathrm{TiO}_{2}$

155.58

$\mathrm{P}_{2} \mathrm{O}_{5}$

0.00

$\mathrm{CaO}$

2022.56

$\mathrm{MgO}$

0.00

$\mathrm{Na}_{2} \mathrm{O}$

0.00

$\mathrm{K}_{2} \mathrm{O}$

0.00

$\mathrm{SO}_{3}$

0.00

\footnotetext{
${ }^{a}$ Approximated as $\mathrm{CH}_{4}$.
} 


\subsubsection{Results of Model Predictions}

The gas-phase species of significance, besides the major gasification components $\left(\mathrm{H}_{2} \mathrm{O}, \mathrm{H}_{2}\right.$, $\mathrm{N}_{2}, \mathrm{CO}_{2}, \mathrm{CH}_{4}, \mathrm{CO}$ ) are $\mathrm{NH}_{3}$ (maximum $0.0021 \mathrm{wt} \%$ ), $\mathrm{HCl}$ (maximum $0.0036 \mathrm{wt} \%$ ), and $\mathrm{HF}$ (maximum $0.0006 \mathrm{wt} \%$ ). None of the gas-phase cerium species considered $\left(\mathrm{Ce}, \mathrm{Ce}_{2}, \mathrm{CeC}_{2}, \mathrm{CeC}_{4}\right.$, $\mathrm{CeO}, \mathrm{CeOH}, \mathrm{CeO}_{2} \mathrm{H}_{2}, \mathrm{CeO}_{3} \mathrm{H}_{3}$ ) appeared in even remotely significant amounts, with the highest, $\mathrm{CeO}_{3} \mathrm{H}_{3}$, having a maximum value of $2.2 \times 10^{-19} \mathrm{wt} \% . \mathrm{Cl}_{2}$ and $\mathrm{F}_{2}$ concentrations were also insignificant.

No liquid-phase species were predicted to form, including the cerium species considered $\left(\mathrm{CeF}_{3}, \mathrm{Ce}_{2} \mathrm{O}_{3}, \mathrm{CeCl}_{3}\right.$, and $\left.\mathrm{Ce}\right)$.

The dominant solid-phase species is $\mathrm{SiO}_{2}$, as would be expected. Minor amounts of calcium silicates, calcium-iron silicates and calcium-titanium silicates are also predicted to be present. Effectively all the cerium in the system is predicted to be present in the solid state as $\mathrm{CeO}_{2}$ and $\mathrm{CeF}_{3}$. Of the solid cerium species considered $\left(\mathrm{Ce}, \mathrm{CeH}_{2}, \mathrm{CeC}_{2}, \mathrm{CeN}, \mathrm{CeO}_{2}, \mathrm{Ce}_{2} \mathrm{O}_{3}, \mathrm{Ce}_{6} \mathrm{O}_{11}, \mathrm{Ce}_{18} \mathrm{O}_{31}, \mathrm{CeF}_{3}\right.$, $\mathrm{CeSi}_{2}$ and $\mathrm{CeCl}_{3}$ ), only $\mathrm{CeO}_{2}$ and $\mathrm{CeF}_{3}$ had nonzero values. The cerium is exclusively in the form of $\mathrm{CeO}_{2}$ above a temperature of $887^{\circ} \mathrm{F}\left(475^{\circ} \mathrm{C}\right)$, below which $\mathrm{CeF}_{3}$ can also form. The two are in approximately equal amounts at $820^{\circ} \mathrm{F}\left(438^{\circ} \mathrm{C}\right)$, below which $68 \%$ of the cerium is $\mathrm{CeF}_{3}$ and $32 \%$ $\mathrm{CeO}_{2}$, as shown in Figure 3.

These predictions represent only the equilibrium thermodynamic behavior; above $887^{\circ} \mathrm{F}$ $\left(475^{\circ} \mathrm{C}\right) \mathrm{CeO}_{2}$ is the thermodynamically stable cerium form. Below this temperature, both $\mathrm{CeO}_{2}$ and $\mathrm{CeF}_{3}$ are thermodynamically stable. The kinetics of conversion between the two, i.e., whether

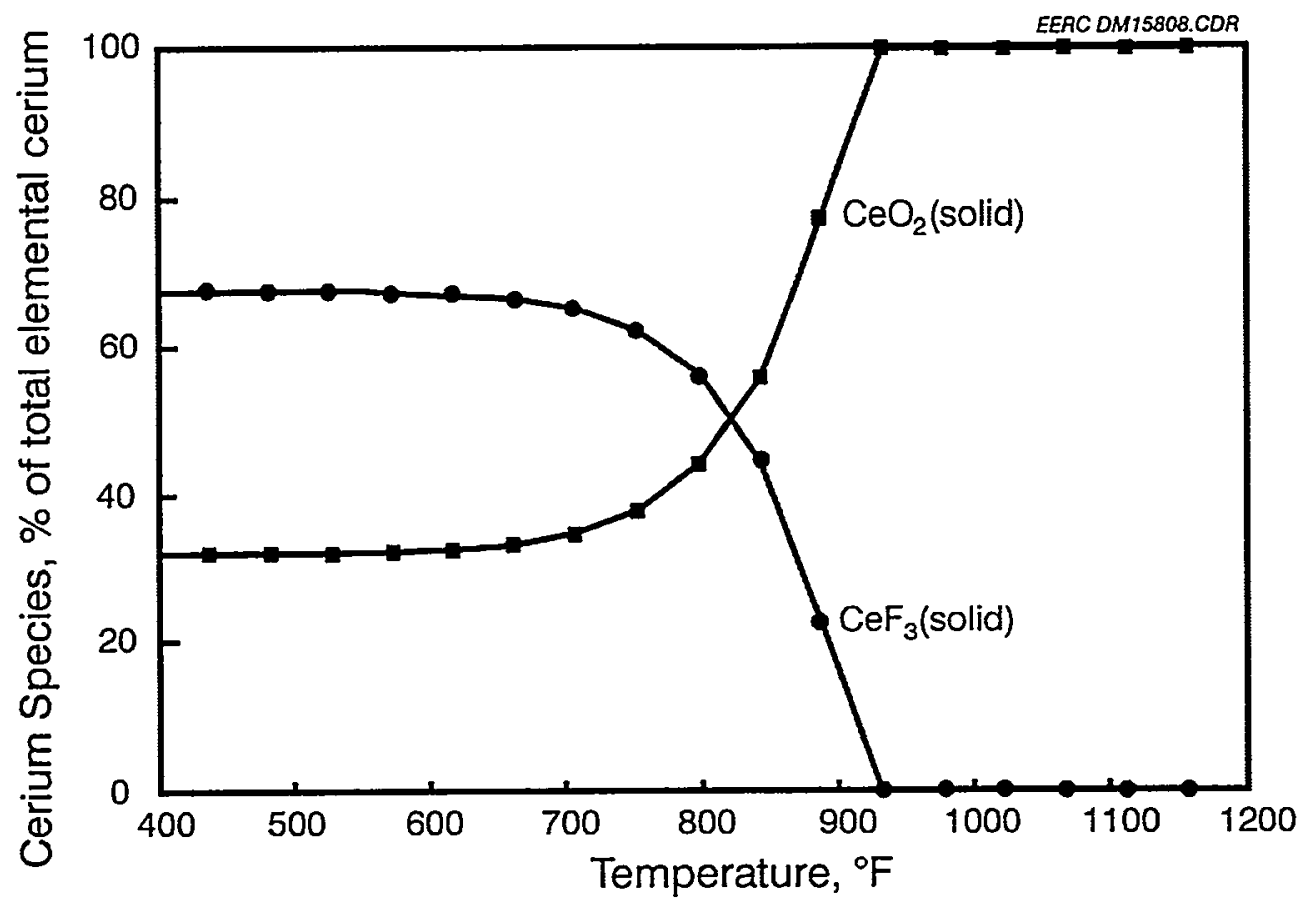

Figure 3. Predicated cerium species. 
equilibrium is achieved, is not addressed by the FACT calculations. The previous examination of HEPA ash with the SEM suggests that the cerium fluoride is converted to the oxide at the higher temperatures in the bed, but remains as cerium oxide at the lower temperatures.

It was concluded that no gas-phase or liquid-phase cerium species are predicted to occur. Cerium is predicted to be present only as solid $\mathrm{CeO}_{2}$ and $\mathrm{CeF}_{3}$ in the system. $\mathrm{CeO}_{2}$ is favored above a temperature of $887^{\circ} \mathrm{F}\left(475^{\circ} \mathrm{C}\right)$, below which both this and $\mathrm{CeF}_{3}$ can occur. Limited SEM morphology and microprobe analysis did not identify significant chlorine or fluorine in combination with $\mathrm{Ce}$, but rather $\mathrm{Ce}$ in combination with small amounts of $\mathrm{Si}, \mathrm{Ca}$, and $\mathrm{Mg}$. Therefore, the dominant cerium form is the oxide, which does not appear to be converted to the fluoride at lower temperatures. This oxide form may be in association with a $\mathrm{Ca}-\mathrm{Si}$ melt phase, which renders it difficult to extract, as demonstrated in the section on chemical Ce analysis.

\subsection{FUTURE WORK}

- Perform experimental characterization of temperature-viscosity profiles to aid in determining vitrification viability for long-term stabilization. Additionally, calculations of viscosity will be performed for several blend combinations to complement the experimentally determined values.

- Conduct leachability tests on the vitrified slags to aid in determining if product leachability falls within U.S. Environmental Protection Agency guidelines and to assess the suitability of the vitrified material for long-term disposal.

\subsection{REFERENCES}

1. ASTM C311 - Salt Fusions as a Dissolution Technique for Atomic Spectroscopy. Spectroscopy, 1991, 6 (4), 44-47.

2. Bale, C.W.; Pelton, A.D.; Thompson W.T. $F^{*} A * C * T 2.1-$ User Manual; Ecole Polytechnique de Montreal/Royal Military College: Canada, July 1996. 